\title{
Can you interpret the ECG under stress?
}

Ching-Hui Sia ${ }^{1}$, MBBS, MRCP, Devinder Singh ${ }^{1,2}$, MD, MRCP, Joshua Ping-Yun $\underline{L o h}^{1,2}, \mathrm{MBBS}, \mathrm{FRCP}$

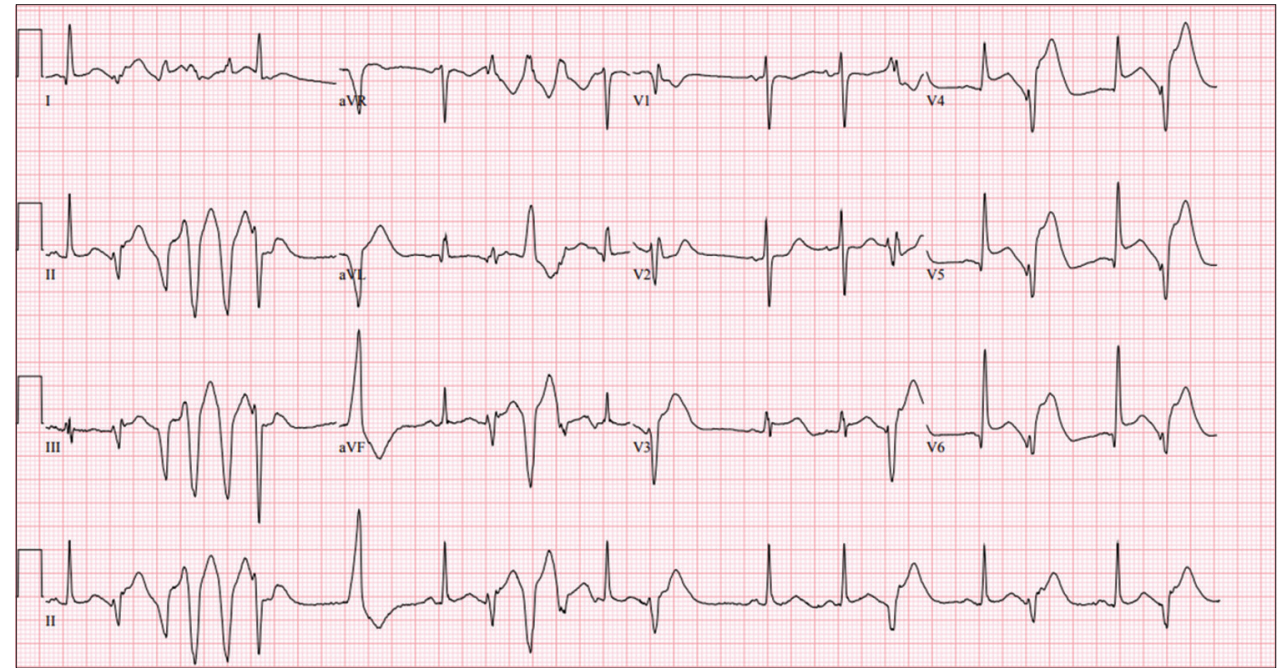

Fig. 1 Case 1: ECG of a 64-year-old woman who presented with central crushing chest pain.

\section{CASE 1}

\section{CLINICAL PRESENTATION}

A 64-year-old woman presented with central crushing chest pain associated with acute nausea, diaphoresis and palpitations on Postoperative Day 2 of a right total knee replacement surgery. She had a background history of diabetes mellitus and dyslipidaemia. Physical examination revealed a soft systolic murmur and an oxygen saturation of $90 \%$ on room air. What does her electrocardiogram (ECG) show (Fig. 1)?

\section{ECG INTERPRETATION}

ECG shows ST elevation in leads V3-V6. Frequent premature ventricular contractions (PVCs), couplets and salvos of PVCs are seen. There is ST segment depression in aVR and V1. The ST segment in V2 is not elevated.

\section{CLINICAL COURSE}

Urgent cardiac catheterisation was performed in view of ongoing chest pain and ST elevation. Coronary angiography showed normal coronary arteries. In view of her hypoxia, computed tomographic pulmonary angiography was performed, which did not demonstrate any pulmonary embolism. Urgent transthoracic echocardiography showed an ejection fraction of $10 \%$ with akinesia at the apex and increased myocardial contraction at the base. The patient subsequently developed cardiogenic shock with multiorgan failure and required venoarterial extracorporeal membrane oxygenation (ECMO) as well as renal replacement therapy. The peak troponin I value was 42,151 ng/L (reference: 0-39 ng/L). ECMO was stopped on the fourth day. The patient subsequently improved clinically and was discharged after a prolonged stay. The patient was treated with bisoprolol. Repeat transthoracic echocardiography four months later showed resolution of the wall motion abnormalities and an ejection fraction of $60 \%$.

\section{CASE 2}

\section{CLINICAL PRESENTATION}

A 35-year-old woman with no significant past medical history was undergoing an elective left hemithyroidectomy for a left thyroid nodule. After anaesthetic induction and upon skin incision, the patient became hypotensive and bradycardic with development

${ }^{1}$ Department of Cardiology, National University Heart Centre Singapore, ${ }^{2}$ Yong Loo Lin School of Medicine, National University of Singapore, Singapore

Correspondence: Dr Joshua Ping-Yun Loh, Assistant Professor, Department of Cardiology, National University Heart Centre Singapore, 1E Kent Ridge Road, NUHS Tower Block Level 9, Singapore 119228. joshua_py_loh@nuhs.edu.sg 


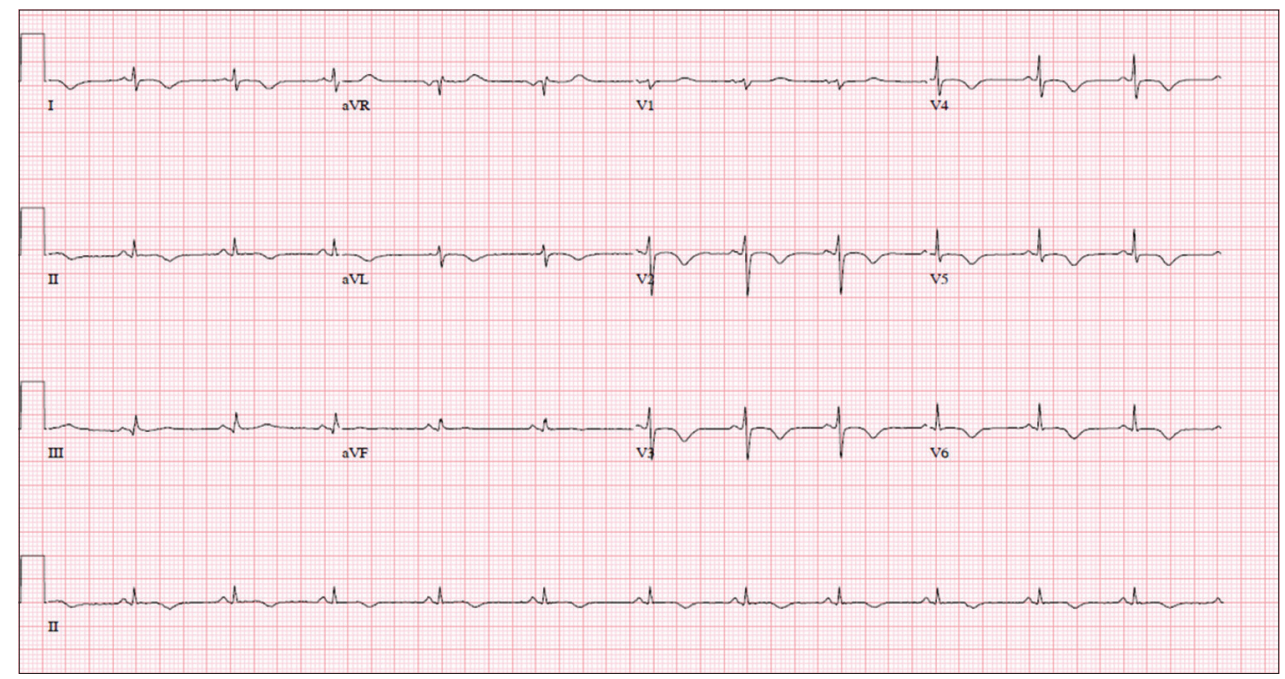

Fig. 2 Case 2: ECG of a 35-year-old woman undergoing an elective left hemithyroidectomy for a left thyroid nodule.
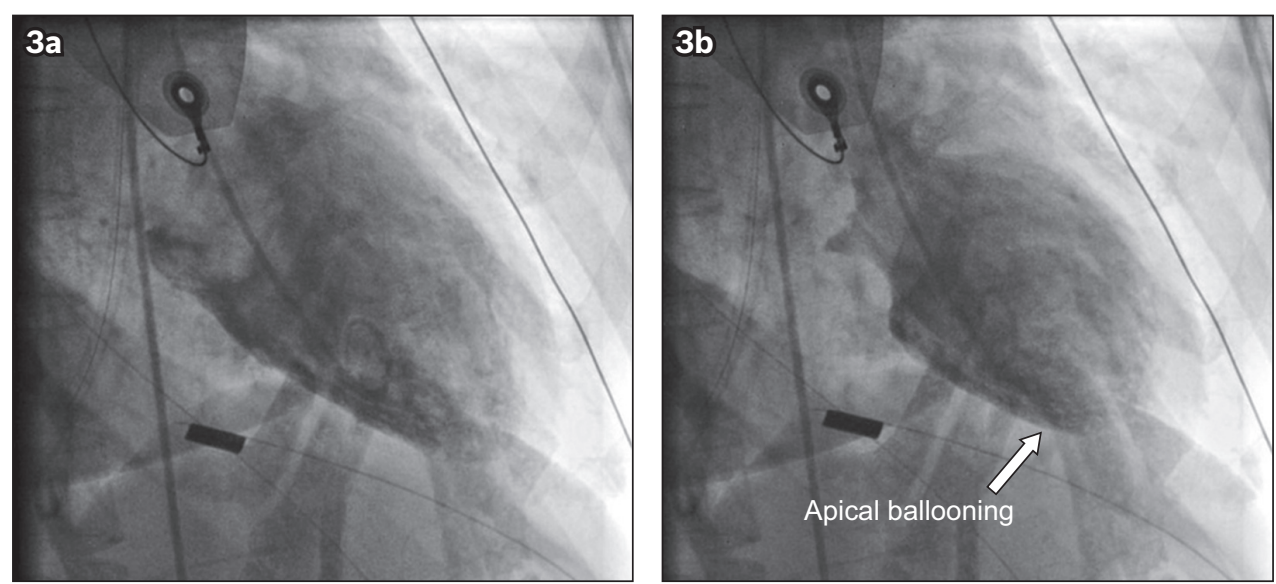

Fig. 3 (a) Diastolic and (b) systolic left ventriculograms show apical to mid-ventricular ballooning with basal hyperkinesis.

of complete heart block (seen on the cardiac monitor). What does the ECG show (Fig. 2)?

\section{ECG INTERPRETATION}

The ECG shows widespread T wave inversion in leads V2-V6, I and $\mathrm{aVL}$, as well as in lead II. The ECG is also low voltage (QRS amplitude $<5 \mathrm{~mm}$ in the limb leads and $<10 \mathrm{~mm}$ in the precordial leads).

\section{CLINICAL COURSE}

In view of her cardiogenic shock, an urgent cardiac catheterisation was performed, which demonstrated normal coronary arteries. Left ventriculography showed the presence of a typical apical ballooning pattern of stress cardiomyopathy (Fig. 3). Her peak troponin I level was 5,380 ng/L (reference: 0-39 ng/L). Transthoracic echocardiography showed apical akinesia with the base being relatively unaffected and an ejection fraction of $30 \%$. The patient was treated with lisinopril. Serum and urinary metanephrine levels were normal. Repeat transthoracic echocardiography performed two months after discharge showed resolution of akinesia and no regional wall motion abnormalities, with recovery of ejection fraction to $65 \%$.

\section{DISCUSSION}

Stress (Takotsubo) cardiomyopathy (SC) is a rare cardiomyopathy typically characterised by transient myocardial dysfunction of the apical or mid-ventricular segments of the left ventricle in the absence of an obstructive coronary anatomy, secondary to a catecholamine surge. The condition is usually self-limiting. ${ }^{(1)}$ The Mayo Clinic diagnostic criteria has been proposed, based on expert consensus, to diagnose the condition and one of the criteria describes new ECG abnormalities (specifically referring to either T wave inversions or ST segment elevations). ${ }^{(1)}$ In stable patients, cardiac magnetic resonance imaging may help to distinguish SC from myocarditis and myocardial infarction, as this imaging modality is able to demonstrate scars and late gadolinium enhancement. In the rest of this paper, we review the literature on the possible ECG manifestations of SC and highlight the myriad of ECG presentations beyond the current existing diagnostic criteria.

\section{Q waves}

SC has been associated with a finding of transient or persistent Q wave formation. ${ }^{(1)}$ 
Table I. Reported electrocardiographic differences between stress cardiomyopathy and acute myocardial infarction.

\begin{tabular}{|c|c|c|}
\hline Entity & Stress cardiomyopathy & Acute myocardial infarction \\
\hline $\begin{array}{l}\text { Non-ST } \\
\text { elevation }\end{array}$ & $\begin{array}{l}\text { - T wave inversions leads extending beyond the } \\
\text { perfusion territory of isolated coronary arteries } \\
\text { - } \quad \text { Positive T wave in aVR } \\
\text { - Lack of negative T waves in V1 } \\
\text { - Greater amplitude of negative T waves }\end{array}$ & $\begin{array}{l}\text { - T wave inversions affect fewer leads } \\
\text { - Smaller amplitude of negative T waves }\end{array}$ \\
\hline ST elevation & $\begin{array}{l}\text { - Less prominent ST elevations } \\
\text { - Less likely to have reciprocal ST-segment depressions } \\
\text { - Less likely to have ST elevation in V1 }\end{array}$ & $\begin{array}{l}\text { - More prominent ST elevations } \\
\text { - More likely to have reciprocal ST-segment depressions } \\
\text { - More likely to have ST elevation in V1 }\end{array}$ \\
\hline In general & $\begin{array}{l}\text { - } \quad \text { ST elevation in -aVR } \\
\text { - } \quad \text { Fewer abnormal Q waves } \\
\text { - Initial attenuation of QRS complexes with } \\
\text { subsequent progressive recovery }\end{array}$ & $\begin{array}{l}\text { - } \text { ST elevation in aVR } \\
\text { - } \text { Persistence of Q waves beyond Day } 2 \text { of event } \\
\text { - Attenuation of QRS complexes remain unchanged from } \\
\text { admission }\end{array}$ \\
\hline
\end{tabular}

\section{QRS complexes}

Studies have described QRS complexes in SC that show low voltages and attenuation of the amplitude of QRS complexes (as in Case 2) in serial ECGs due to myocardial oedema, with a corresponding shortening of the QRS duration. ${ }^{(1,2)}$

\section{ST segment}

ST elevation in -aVR (i.e. ST depression in aVR) with various permutations of ST elevation and $\mathrm{T}$ wave inversions are characteristic of SC. ${ }^{(3)}$ It is of particular interest that ST elevation seldom affects $\mathrm{V} 1$, as the akinetic segments are situated away from the $\mathrm{V} 1$ lead. ${ }^{(4)}$

\section{T waves}

SC patients have diffuse T wave inversions extending throughout multiple leads, and the depth of the inversions correlates with the magnitude of myocardial oedema. ${ }^{(4)} \mathrm{A}$ positive $\mathrm{T}$ wave in $\mathrm{aVR}$ and a lack of negative $\mathrm{T}$ wave in $\mathrm{V} 1$ are highly sensitive and specific for SC. ${ }^{(1)}$ Rarer T wave manifestations have also been reported. A Wellens' syndrome-type ECG pattern with biphasic $\mathrm{T}$ waves has previously been reported and has been attributed to a gradient of myocardial oedema on the left ventricle seen on cardiac magnetic resonance imaging. ${ }^{(5)}$

\section{QT interval}

SC has been associated with abnormalities in ventricular repolarisation, causing a prolongation of the QT interval, and is a known cause of acquired long QT syndrome. ${ }^{(1)}$ QT dispersion and $\mathrm{T}_{\text {peak }}$-to- $\mathrm{T}_{\text {end }}$ are also increased. Reversal of all the above intervals in the chronic phase has been reported. ${ }^{(6)}$

\section{Arrhythmias}

SC patients may present with a variety of tachyarrhythmia and bradyarrhythmia. Tachycardias include atrial fibrillation as well as more serious rhythms such as torsades de pointes (in association with the prolongation of QTC), polymorphic ventricular tachycardia and ventricular fibrillation. ${ }^{(7-10)}$ Bradycardias include conduction blocks of various degrees. ${ }^{(11)}$

\section{Other ECG presentations}

SC may present as a new-onset left bundle branch block mimicking ST elevation myocardial infarction, and this has been reported in up to $9 \%$ of patients in one study. ${ }^{(12)}$

\section{Studies comparing SC with other conditions}

Differentiating SC from other conditions, in particular acute myocardial infarction (AMI), is of interest because of the potential implications on therapy upon presentation. ${ }^{(13)} \mathrm{A}$ summary of the reported ECG differences between SC and AMI are presented in Table I. ${ }^{(1,4,9,14-17)}$ The ECGs of SC and AMI patients are subdivided into those with ST elevations and those without. It is worth noting that several studies have disputed the use of ECG criteria to differentiate between SC and AMI. ${ }^{(17)}$

Interestingly, the ECG changes of SC may resemble those of acute pericarditis, with more diffuse ST segment elevations, concave ST segment elevations and depressed PR segments. ${ }^{(18)}$ It is postulated that this possibly reflects acute circumferential subepicardial ischaemia in SC. ${ }^{(18)}$

\section{ECG markers of prognosis}

Longer QT intervals are associated with poorer outcomes. These patients are more likely to present with dyspnoea and to have higher levels of $\mathrm{N}$-terminal pro B-type natriuretic peptide. They are also more likely than those with a normal QT interval to require re-hospitalisation, mechanical ventilation and vasopressors for shock, as well as develop arrhythmias and die.(19) Prolonged QRS duration is also associated with higher in-hospital mortality, cardiac death, ventilator use, ventricular arrhythmias and circulatory failure. ${ }^{(20)}$ Other reported adverse prognostic markers include a higher heart rate and larger sum of ST elevations in all 12 leads. ${ }^{(21)}$ Persistent $Q$ waves are a poor prognostic marker. ${ }^{(4)}$ There are no reported differences in clinical complications in patients presenting with ST or non-ST elevation ECGs in SC.(22)

\section{Other considerations}

The ECG manifestations of SC could vary depending on the type of SC. The apical or combined apical and mid-ventricular variants have been associated with ST elevations, while the 
mid-ventricular variants alone have been associated with T wave inversions. ${ }^{(22)}$ ECG changes more often affect all leads in apical variants, while only leads $\mathrm{V} 2$ and $\mathrm{V} 3$ are affected in the mid-ventricular variants. ${ }^{(23)} \mathrm{SC}$ can coexist with other pathologies (e.g. acute pericarditis), complicating ECG interpretation. ${ }^{(24)}$ Ethnic differences in ECG presentations have also been described, with Asian patients having more ST segment elevations as compared to Caucasians. ${ }^{(25)}$ However, there has not been any reported ECG differences between male and female patients. ${ }^{(22)}$

\section{CONCLUSION}

This paper discussed two cases of SC with ECG manifestations. It also described the reported ECG manifestations of SC. Practitioners should take note of these clinical presentations to heighten their suspicion so as to successfully diagnose this cardiomyopathy.

ABSTRACT Stress (Takotsubo) cardiomyopathy (SC) is a cardiomyopathy characterised by transient myocardial dysfunction, commonly triggered by a surge in catecholamine. Electrocardiographic features may mimic other conditions, such as myocardial infarction. We presented two cases of SC and reviewed the electrocardiographic features of this disease entity.

Keywords: electrocardiography, stress cardiomyopathy, ST elevation, Takotsubo, $T$ wave inversion

\section{REFERENCES}

1. Duran-Cambra A, Sutil-Vega M, Fiol M et al. Systematic review of the electrocardiographic changes in the Takotsubo syndrome. Ann Noninvasive Electrocardiol 2015; 20:1-6.

2. Madias JE, Macfarlane PW. Artificial attenuation of ECG voltage produces shortening of the corresponding QRS duration: clinical implications for patients with edema. Pacing Clin Electrophysiol 2005; 28:1060-5.

3. Frangieh $\mathrm{AH}$, Obeid S, Ghadri JR, et al; InterTAK Collaborators. ECG criteria to differentiate between takotsubo (stress) cardiomyopathy and myocardial infarction. J Am Heart Assoc 2016; 5:e003418.

4. Thakar S, Chandra P, Hollander G, Lichstein E. Electrocardiographic changes in Takotsubo cardiomyopathy. Pacing Clin Electrophysiol 2011; 34:1278-82.

5. Perazzolo Marra M, Zorzi A, Corbetti F, et al. Apicobasal gradient of left ventricular myocardial edema underlies transient T-wave inversion and QT interval prolongation (Wellens' ECG pattern) in Tako-Tsubo cardiomyopathy. Heart Rhythm 2013; 10:70-7.

6. Mugnai G, Vassanelli F, Pasqualin G, et al. Dynamic changes of repolarization abnormalities in takotsubo cardiomyopathy. Acta Cardiol 2015; 70:225-32.
7. Hasdemir C, Vuran O, Yuksel A, Yavuzgil O. Stress cardiomyopathy (TakoTsubo) associated with sustained polymorphic ventricular tachycardia. Pacing Clin Electrophysiol 2013; 36:e111-4.

8. Madias J. A patient with ventricular fibrillation and inverted Takotsubo syndrome triggered by sinus surgery: plausible causes, and electrocardiographic features. Turk Kardiyol Dern Ars 2016; 44:535.

9. Namgung J. Electrocardiographic findings in Takotsubo cardiomyopathy: ECG evolution and its difference from the ECG of acute coronary syndrome. Clin Med Insights Cardiol 2014; 8:29-34.

10. Valbusa A, Ingrassia S, Rosa GM, et al. Takotsubo cardiomyopathy and torsade de pointes in myasthenic crisis: be aware of QT prolongation. Am J Emerg Med 2013; 31:1717-8.

11. Cativo EH, Valvani R, Mene-Afejuku TO, Cativo DP, Mushiyev S. A rare association of Takotsubo cardiomyopathy with high-degree atrioventricular block. Case Rep Cardiol 2017; 2017:6989438.

12. Parodi G, Salvadori C, Del Pace S, et al; Tuscany Registry of Tako-Tsubo Cardiomyopathy. Left bundle branch block as an electrocardiographic pattern at presentation of patients with Tako-tsubo cardiomyopathy. J Cardiovasc Med (Hagerstown) 2009; 10:100-3.

13. Kuntjoro I, Teo SG, Poh KK. Electrocardiography series. Non-ischaemic causes of ST segment elevation. Singapore Med J 2012; 53:367-71.

14. Looi JL, Wong CW, Lee M, et al. Usefulness of ECG to differentiate Takotsubo cardiomyopathy from acute coronary syndrome. Int J Cardiol 2015; 199:132-40.

15. Masami K, Ebina T, Hibi K, et al. Differences in negative $T$ waves among acute coronary syndrome, acute pulmonary embolism, and Takotsubo cardiomyopathy. Eur Heart J Acute Cardiovasc Care 2012; 1:349-57.

16. Mugnai G, Pasqualin G, Benfari G, et al. Acute electrocardiographic differences between Takotsubo cardiomyopathy and anterior ST elevation myocardial infarction. J Electrocardiol 2015; 48:79-85.

17. Parkkonen O, Allonen J, Vaara S, et al. Differences in ST-elevation and T-wave amplitudes do not reliably differentiate takotsubo cardiomyopathy from acute anterior myocardial infarction. J Electrocardiol 2014; 47:692-9.

18. Zhong-qun Z, Chong-quan W, Sclarovsky S, et al. ST-segment deviation pattern of takotsubo cardiomyopathy similar to acute pericarditis: diffuse ST-segment elevation. J Electrocardiol 2013; 46:84-9.

19. Santoro F, Brunetti ND, Tarantino N, et al. Dynamic changes of QTc interval and prognostic significance in takotsubo (stress) cardiomyopathy. Clin Cardiol 2017; 40:1116-22.

20. Yamaguchi T, Yoshikawa T, Isogai T, et al. Predictive value of QRS duration at admission for in-hospital clinical outcome of Takotsubo cardiomyopathy. Circ J 2016; 81:62-8.

21. Takashio S, Yamamuro M, Kojima S, et al. Usefulness of SUM of ST-segment elevation on electrocardiograms (limb leads) for predicting in-hospital complications in patients with stress (takotsubo) cardiomyopathy. Am J Cardiol 2012; 109:1651-6.

22. Weihs V, Szücs D, Fellner B, et al. Electrocardiogram changes and wall motion abnormalities in the acute phase of Tako-Tsubo syndrome. Eur Heart J Acute Cardiovasc Care 2016; 5:481-8.

23. Kurisu S, Kato Y, Mitsuba N, et al. Comparison of electrocardiographic findings between the midventricular ballooning form and apical ballooning form of takotsubo cardiomyopathy. Clin Cardiol 2011; 34:555-9.

24. Peters S. Takotsubo cardiomyopathy and electrocardiographic signs of perimyocarditis-findings of coronary angiography. Int J Cardiol 2016; 223:790.

25. Núñez-Gil IJ, Luaces M, Garcia-Rubira JC, Zamorano J. Electrocardiographic criteria in Takotsubo cardiomyopathy and race differences: Asians versus Caucasians. J Am Coll Cardiol 2010; 56:1433-4. 


\section{SINGAPORE MEDICAL COUNCIL CATEGORY 3B CME PROGRAMME} (Code SMJ 201809A)

Question 1. Patients with stress cardiomyopathy (SC) may present with:
(a) Chest pain
(b) Palpitations.
(c) Leg pain.
(d) Diaphoresis.

Question 2. Regarding SC:

(a) It is characterised by transient myocardial dysfunction of the apical or mid-ventricular segments of the left ventricle.

(b) The condition is usually self-limiting.

(c) It can be diagnosed using the Mayo Clinic diagnostic criteria.

(d) It may be differentiated from myocarditis and myocardial infarction via cardiac magnetic resonance imaging.

Question 3. Electrocardiographic findings of patients with SC may include:
(a) ST segment elevation.
(b) Premature ventricular contractions.
(c) T wave inversions.
(d) Increase in the voltages of QRS complexes.

Question 4. Investigative findings of patients with SC may include:
(a) A normal coronary angiogram.
(b) Reduced ejection fraction on echocardiography.
(c) Raised troponin level.
(d) Heart failure findings on chest radiography.

Question 5. Known factors that may affect interpretation of electrocardiographic changes in SC include:
(a) Type of SC.
(b) Concomitant cardiac pathologies.
(c) Ethnicity.
(d) Gender.

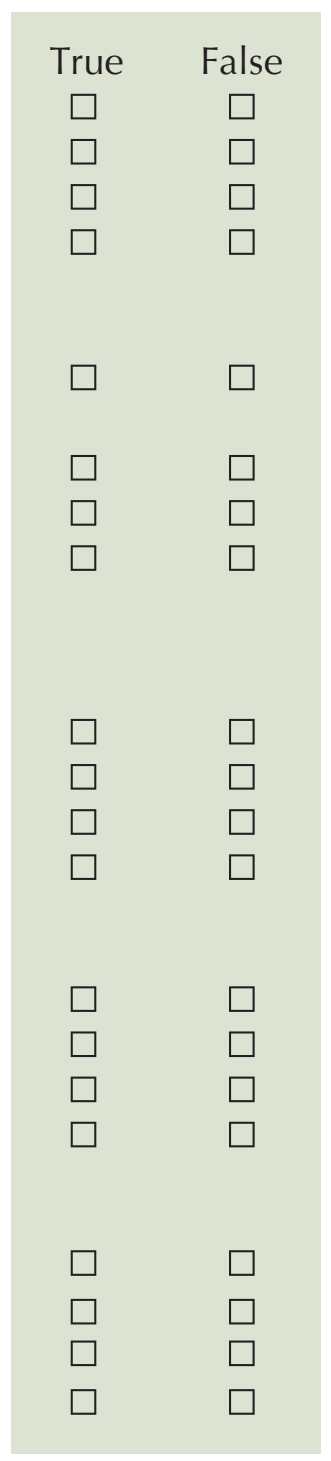

\section{Doctor's particulars:}

Name in full: MCR no:

Specialty:

Email:

\section{SUBMISSION INSTRUCTIONS}

Visit the SMJ website: http://www.smj.org.sg/current-issue and select the appropriate quiz. You will be redirected to the SMA login page.

For SMA member: (1) Log in with your username and password (if you do not know your password, please click on 'Forgot your password?'). (2) Select your answers for each quiz and click 'Submit'.

For non-SMA member: (1) Create an SMJ CME account, or log in with your SMJ CME username and password (for returning users). (2) Make payment of SGD 21.40 (inclusive of $7 \%$ GST) via PayPal to access this month's quizzes. (3) Select your answers for each quiz and click 'Submit'.

\section{RESULTS:}

(1) Answers will be published online in the SMJ November 2018 issue. (2) The MCR numbers of successful candidates will be posted online at the SMJ website by 7 November 2018. (3) Passing mark is $60 \%$. No mark will be deducted for incorrect answers. (4) The SMJ editorial office will submit the list of successful candidates to the Singapore Medical Council. (5) One CME point is awarded for successful candidates. (6) SMC credits CME points according to the month of publication of the CME article (i.e. points awarded for a quiz published in the December 2017 issue will be credited for the month of December 2017, even if the deadline is in January 2018).

Deadline for submission (September 2018 SMJ 3B CME programme): 12 noon, 31 October 2018. 